\title{
Management of the Upcoming Storm of Post-COVID Spectrum of Psychological Disorders
}

\author{
Hima Bindu Ponnam ${ }^{1 *}$ and Butchi Raju Akondi \\ 'Drug Standardization Unit (Homoeopathy), Central Council for Research in Homoeopathy, \\ Under Ministry of AYUSH, Government of India, Hyderabad, Telangana, India; himabindu@ccrhindia.nic.in \\ ${ }^{2}$ Department of Clinical Pharmacy and Pharmacology, Ibn Sina National College for Medical Studies, Jeddah, \\ Saudi Arabia; drraju2020@gmail.com
}

\section{Introduction}

India is a country with rich culture and heritage gifted from its ancestors. India is striving to improvise the public health care delivery framework of the country towards a very eco-friendly and easily accessible manner by integrating its culture and heritage with modern medical science. Many visionary steps are being taken by the Indian Government for its implementation through the integration of Indian systems of medicine (Ayush - Ayurveda, Yoga, Unani, Siddha, Sow-Rigpa, and Homoeopathy) with modern medical science (Allopathy). Although this integration started a decade ago, the actual practical implementation took a rapid swing during the COVID-19 pandemic in the country. Telehealth and virtual consultations have surged during the pandemic as physical consultations were risky ${ }^{1,2}$. Even after such advancements are vogue yet some cultural myths and taboos ruled people disrupting crucial medical services as psychotherapy away from the usual health care delivery system. The Majority of the people of the country visualize psychotherapy as a taboo and psychological illness as an insulting label for any individual even today and it is a known fact that this pandemic has rooted many psychological illnesses which are to be addressed appropriately. Unlike western countries, even now people of India never voluntarily reach out for a psychotherapist seeking medical help unless things outbreak and reach a considerably explosive state ${ }^{3}$.

The prevalence of mental disorders is evolving its wings at a rapid pace for a decade. If we see the prevalence data of 2010, mental, neurological and substance abuse disorders showed $10.4 \%$ of global Daily Adjusted Life Years (DALYs) and among them again mental disorders accounted for a large proportion of DALYs (56.7\%). Overall, the lifetime prevalence of mental disorders accounts for $5.03 \%{ }^{5}$. As per the 2015-16 National Mental Health Survey of India, the prevalence accounted for $13 \%$ (DALYs) ${ }^{6}$ and as per WHO 2019 report, the prevalence of mental disorders was estimated as $22.1 \%$. Among them, the most common mental disorders identified are depression, anxiety disorders, post-traumatic stress disorders, bipolar disorders, and schizophrenia ${ }^{7}$. The sequential rise in mental disorders continued and furthermore became a major public health concern during the current COVID19 pandemic. As per a few surveys conducted during the first and second waves of the pandemic, the incidence of mental disorders accounted for almost $28.2 \%$ and among them, post-traumatic stress disorder was found to be commonly diagnosed ${ }^{8-11}$. According to a previous metaanalysis, $17-44 \%$ of critical illness survivors especially

${ }^{*}$ Author for correspondence 
those who required hospitalization/ICU reported clinically significant PTSD symptoms ${ }^{12,13}$.

\section{Major Psychological Manifestations Post-COVID}

A wide range of psychological manifestations posing as a major public health concern post-COVID are identified as below:

1. Anxiety disorders $\mathrm{s}^{8,10,15}$

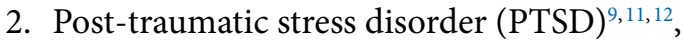

3. Obsessive compulsive disorders (OCD $)^{14}$

4. Phobias ${ }^{15}$ and

5. Depression ${ }^{11}$.

And addressing these immediate psychological states is very important as untreated may result in an array of more dangerous long-term psychological illnesses threatening human life.

\section{Psychotherapeutic Interventions}

Usually, psychotherapy is classified into five broad categories as:

1. Psychoanalysis and psychodynamic therapies.

2. Behavioural therapy.

3. Cognitive therapy.

4. Humanistic therapy.

5. Integrative or holistic therapy.

Among the above all, psychodynamic, cognitive, and behavioural therapies are the best and the most appropriately identified means of managing the abovementioned post-COVID psychological states as suggested by previous studies ${ }^{16}$. These two therapies form the evidence-based recommendations for traumarelated psychological manifestations ${ }^{17}$. The psychological manifestations developing during or after a specific horrifying event indicate trauma to the mind. Though the presentation of the symptomatology may vary from person to person, the diagnosis indicates the posttraumatic state of mind most commonly considered as a post-traumatic stress disorder. This state may be visualized as a temporary condition but if not appropriately dealt may land the individual into chronic states of mind like depression, OCD, and other chronic anxiety disorders later with its threatening impact on physical health even.

\section{Futuristic Perspectives}

The devastating COVID-19 pandemic has completely changed the scenario of health care at a rapid pace with upcoming challenges ${ }^{18}$. In order to serve the needs of the community in regards to their psychological manifestations during the pandemic, the field of psychiatry should raise to the level of advanced technology as videoconferencing and telemedicine for ensuring mental health to make easily accessible to the public ${ }^{19,20}$. An integration of Tele-psychology and Tele-counselling should be a part of the routine health care services for easy access and must create awareness among people about mental disorders. It further would help to remove the myths and taboos about psychological disorders.

Previously many online-based psychological counselling was taken up through social networking platforms ${ }^{21}$ with positive outcomes. Keeping in view the present need for psychological counselling during the pandemic - authenticated psychological organizations with public-private collaborative partnerships should focus on a global vision by promoting specific training for psychologists and psychotherapists as developing the basic skills in managing the effects of a pandemic and emergency situations and also sensitizing patients to online therapeutic rapport providing standard operating procedures (SOPs) ${ }^{22}$.

Psychiatrists, psychologists from the public, private sectors, and non-governmental organizations should all associate with each other and start affiliating to community clubs, local societies, etc. to cater to the pandemic mitigation plans as envisaged by $\mathrm{WHO}$ and the Health and Family Welfare Ministry of our Government. Thus, the integration of psychotherapy in the essential health services of the pandemic would further strengthen the roots of mental health care delivery of our country and also nurtures an easy accessibility for every citizen enriching the future health care vision of India. ${ }^{23}$

\section{References}

1. Telemedicine Practice Guidelines. MOHFW $20^{\text {th }}$ Mar 2020. Telemedicine.pdf (mohfw.gov.in) [Accessed on $3^{\text {rd }}$ June 2021]. 
2. Telemedicine Practice Guidelines, Central Council of Homoeopathy. Available from: https://www.ayush.gov.in/ docs/126.pdf. Accessed on April 15, 2020.

3. Kishore J, Gupta A, Jiloha RC, Bantman P. Myths, beliefs and perceptions about mental disorders and health-seeking behavior in Delhi, India. Indian J Psychiatry. 2011 Oct-Dec; 53(4): 324-329. https://doi.org/10.4103/0019-5545.91906 PMid:22303041 PMCid:PMC3267344

4. Whiteford HA, Ferrari AJ, Degenhardt L, Feigen V, Vos T. The Global Burden of Mental, Neurological and Substance Use Disorders: An Analysis from the Global Burden of Disease Study 2010. PLos One. 2015; 10(2): e0116820. https://doi.org/10.1371/journal.pone.0116820 PMid:25658103 PMCid:PMC4320057

5. Deswal BS, Pawar A. An epidemiological study of mental disorders at Pune, Maharashtra. Indian J Community Med. 2012; 37: 116-21. https://doi.org/10.4103/0970-0218.96097 PMid:22654285 PMCid:PMC3361794

6. Gururaj G, Varghese M, Benegal V, Rao GN, Pathak K, Singh LK et al.,. National Mental Health Survey of India, 2015-16: Summary. Bengaluru, National Institute of Mental Health and Neuro Sciences, NIMHANS Publication No. 128, 2016. www.indianmhs.nimhans.ac.in/Docs.Summary. pdf [Accessed on 12.10.2021]

7. Charlson F, Ommeren MV, Flaxman A, Cornett J, Whiteford H, Saxena S. New WHO prevalence estimates of mental disorders in conflict settings: a systematic review and meta-analysis. The Lancet. 2019; 394(10194): 240-48. https://doi.org/10.1016/S0140-6736(19)30934-1

8. Guessoum, S. B., Lachal, J., Radjack, R., Carretier, E., Minassian, S., Benoit, L., \& Moro, M. R. Adolescent psychiatric disorders during the COVID-19 pandemic and lockdown. Psychiatry Res. 2020; 291: 113264. https:// doi.org/10.1016/j.psychres.2020.113264 PMid: 32622172 PMCid: PMC7323662

9. Ponnam HB, Akondi BR. Post-COVID Stress Disorder: An Emerging Upshot of the COVID-19 Pandemic. Asian Journal of Pharmaceutical Research and Health Care. 2021; 13(2): 123-124. https://doi.org/10.18311/ ajprhc/2021/27648

10. Cao C, Wang L, Fang R, Liu P, Bi Y, Luo S, Grace E, Olff M. Anxiety, depression, and PTSD symptoms among high school students in china in response to the COVID19 pandemic and lockdown [published online ahead of print, 2021 Sep 22]. J Affect Disord. 2021; 296:126-129. https://doi.org/10.1016/j.jad.2021.09.052 PMid:34601299 PMCid:PMC8456154

11. Singh SP, Khokhar A. Prevalence of Posttraumatic Stress Disorder and Depression in General Population in India During COVID-19 Pandemic Home Quarantine [pub- lished online ahead of print, 2020 Nov 16]. Asia Pac J Public Health. 2020; 1010539520968455. https://doi. org/10.1177/1010539520968455 PMid:33198479

12. Giannopoulou, I., Galinaki, S., Kollintza, E., Adamaki, M., Kympouropoulos, S., Alevyzakis, E., Tsamakis, K., Tsangaris, I., Spandidos, D. A., Siafakas, N., Zoumpourlis, V., \& Rizos, E. COVID-19 and post-traumatic stress disorder: The perfect 'storm' for mental health (Review). Exp Ther Med. 2021; 22(4): 1162. https://doi.org/10.3892/ etm.2021.10596 PMid:34504607 PMCid:PMC8392877

13. Parker AM, Sricharoenchai T, Raparla S, Schneck KW, Bienvenu OJ and Needham DM: Posttraumatic stress disorder in critical illness survivors: A metaanalysis. Crit Care Med 2015; 43: 1121-1129. https://doi.org/10.1097/ CCM.0000000000000882 PMid:25654178

14. Jelinek L, Moritz S, Miegel F, Voderholzer U. Obsessivecompulsive disorder during COVID-19: Turning a problem into an opportunity?. J Anxiety Disord. 2021; 77: 102329. https://doi.org/10.1016/j.janxdis.2020.102329 PMid:33190017 PMCid:PMC7644184

15. Arora A, Jha AK, Alat P, Das SS. Understanding coronaphobia. Asian J Psychiatr. 2020; 54: 102384. https://doi. org/10.1016/j.ajp.2020.102384 PMid: 33271693 PMCid: PMC7474809

16. Levi, O., Bar-Haim, Y., Kreiss, Y., and Fruchter, E. CognitiveBehavioural Therapy and Psychodynamic Psychotherapy in the Treatment of Combat-Related Post-Traumatic Stress Disorder: A Comparative Effectiveness Study. Clin. Psychol. Psychother. 2016; 23: 298-307. https://doi.org/10.1002/ cpp.1969 PMid:26189337

17. Paintain, E. and Cassidy, S. First-line therapy for post-traumatic stress disorder: A systematic review of cognitive behavioural therapyand psychodynamicapproaches. Couns. Psychother. Res. 2018; 18: 237-250. https://doi.org/10.1002/ capr.12174 PMid:30147450 PMCid:PMC6099301

18. Türközer, H.B., Öngür, D. A projection for psychiatry in the post-COVID-19 era: potential trends, challenges, and directions. Mol Psychiatry. 2020; pp. 2214-2219 https://doi. org/10.1038/s41380-020-0841-2 PMid: 32681098 PMCid: PMC7366480

19. ChiauzziE, Clayton A,Huh-YooJ. Videoconferencing-Based Telemental Health: Important Questions for the COVID19 Era from Clinical and Patient-Centered Perspectives. JMIR Ment Health. 2020; 7(12): e24021. https://doi. org/10.2196/24021 PMid:33180739 PMCid:PMC7725495

20. Saladino V, Algeri D and Auriemma V. The Psychological and Social Impact of Covid-19: New Perspectives of Well-Being. Front. Psychol. 2020; 11: 577684. https://doi. org/10.3389/fpsyg.2020.577684 PMid:33132986 PMCid: PMC7561673 
21. Gabri, S., Mazzucchelli, S., and Algeri, D. The request for psychological help in the digital age: offering counseling through chat and video counseling. E J. Psychother. 2015, p. 2-10.

22. Stoll, J., Müller, J., and Trachsel, M. Ethical Issues in Online Psychotherapy: A Narrative Review. Front. Psych.
2020; 10: 993. https://doi.org/10.3389/fpsyt.2019.00993 PMid:32116819 PMCid:PMC7026245

23. Manickam L, Roy P. COVID-19 pandemic: challenges and responses of psychologists from india. $1^{\text {st }} \mathrm{ed}$. Thiruvananthapuram; 2021. 